\title{
A comparison of the costs of bronchodilator delivery methods in children with asthma exacerbations treated in hospital. The first Polish study in children
}

\author{
Kamil Janeczek ${ }^{1}$, Anna Bodajko-Grochowska ${ }^{1}$, Andrzej Emeryk ${ }^{1}$, Iwona Czerwińska-Pawluk ${ }^{2}$ \\ ${ }^{1}$ Department of Pulmonary Diseases and Children Rheumatology, Medical University of Lublin, Lublin, Poland \\ 2Pulmonary Function Testing Laboratory, Children's University Hospital, Lublin, Poland
}

Adv Dermatol Allergol 2021; XXXVIII (6): 1011-1016

DOI: https://doi.org/10.5114/ada.2020.98131

\begin{abstract}
Introduction: Recommended methods of administering bronchodilator drugs in children with asthma exacerbations in a hospital include the pressurized metered-dose inhaler (pMDI) and nebulization (NEB). These methods differ in clinical effectiveness, safety and, as some studies indicate, the cost of their use in a child.

Aim: To calculate the direct costs of hospital therapy conducted with the use of short-acting $\beta_{2}$-agonist (SABA) or its combination with short-acting muscarinic antagonist (SAMA) administered via pMDI with valved holding chamber (VHC) versus the same drugs in NEB in children with asthma exacerbation.

Material and methods: A retrospective analysis of the costs of SABA (salbutamol) and SABA + SAMA (fenoterol + ipratropium bromide) inhalation therapy was performed. Based on the data obtained from the financial department, the pharmacy, and the sterilization department of the university hospital, the direct unit cost of the inhalation therapy in the child was calculated.

Results: The results of the analysis indicate that in a hospital setting the cost of one-time SABA or SABA + SAMA administration via $\mathrm{pMDI}+\mathrm{VHC}$ is 1.5-2.4 times lower compared to NEB. The payer incurred the lowest costs during anti-obstructive treatment using SABA with pMDI + VHC (PLN 9.39 for one inhalation procedure). The working time of medical staff during the inhalation treatment is the component generating the highest cost for the hospital (up to $40 \%$ of direct costs).

Conclusions: In hospital conditions, the supply of SABA or SABA + SAMA with the use of pMDI + VHC in a child with asthma exacerbation is more beneficial financially than the supply of the same drugs in NEB.
\end{abstract}

Key words: nebulization, pressurized metered-dose inhaler, bronchodilator, asthma, children.

\section{Introduction}

Short-acting $\beta_{2}$-agonists (SABA) or their combination with short-acting muscarinic antagonists (SAMA) in inhalation are among the most important anti-obstructive drugs. These drugs are used in many diseases with acute bronchial obstruction in children, such as asthma, bronchitis, bronchiolitis, bronchopulmonary dysplasia, and pulmonary exacerbation of cystic fibrosis. They are available in the following inhalation forms: pressurized metered-dose inhaler (pMDI), breath-actuated pressurized metered-dose inhaler (pMDI-BA), metered-dose liquid inhaler (MDLI), dry powder inhaler (DPI) and as solutions for nebulization (NEB) [1-6].

Rational health policy is based on pharmacoeconomic analyses. These analyses help in choosing the method of treatment of a given disease - which one is most costeffective while maintaining the highest clinical effective- ness. Research to date has shown that SABA as well as the combination of SABA and SAMA used in aerosol therapy of respiratory diseases may differ not only in the method of administration, but also in clinical effectiveness, safety and costs associated with their use in patients [3, 7-9]. Research results indicate that regardless of the calculation method, the use of SABA with PMDI in combination with a valved holding chamber $(\mathrm{VHC})$ instead of NEB is associated with a reduction in total costs in both the emergency department and the hospital ward [10-15]. There has been no similar analysis carried out in Poland.

\section{Aim \\ The aim of the study was to estimate the total direct costs of bronchial obstruction therapy in children with}


asthma exacerbation using SABA or a combination of SABA and SAMA administered via PMDI + VHC versus the same drugs in NEB in a hospital ward setting.

\section{Material and methods}

An analysis was carried out of the costs of inhalation therapy SABA (salbutamol) and SABA (fenoterol) in combination with SAMA (ipratropium bromide) conducted in children with asthma exacerbation in a hospital setting from the payer's perspective. The direct costs of two inhalation therapy methods ( $\mathrm{pMDI}+\mathrm{VHC}, \mathrm{NEB})$ used in the non-invasive treatment wards of the University Children's Hospital in Lublin were calculated (in accordance with the hospital procedure for the administration of inhaled drugs number PPO7/2018) taking into account direct medical costs (cost of drugs, devices for their administration, remuneration for medical staff) as well as direct non-medical costs (cost of personal protective equipment, sterilization of drug delivery devices) $[16,17]$. The sources of data necessary to calculate the above-mentioned costs are presented in Table 1.

The actual cost of one inhalation procedure was estimated for the doses of drugs recommended for an average child aged 6 years with bronchial obstruction, in whom bronchodilators were administered via PMDI + VHC (with a mouthpiece) or via a nebulizer through the mouthpiece according to current recommendations [5]. At the University Children's Hospital in Lublin, bronchodilator drugs are mainly delivered by VHC, such as AeroChamber Plus Flow-Vu and RespiChamber Hospital ${ }^{\circledR}$ as well as by the OMRON A3 Complete ${ }^{\circledast}$ jet nebulizer and the Intec Twister Mesh ${ }^{\oplus}$ nebulizer. The technical characteristics of the tested inhalation devices are summarized in Table 2. The calculations also took into account drug losses during filling residual volume of nebulizers (RV). The average duration of the inhalation procedure was based on data from the Mason et al. study (Table 1), while the lifespan of inhalation drug delivery devices was adopted according to the manufacturer's recommendations [18].

Table 1. Output sources

\begin{tabular}{|c|c|}
\hline Variables and model parameters & Data sources \\
\hline Drug costs & $\begin{array}{l}\text { Data obtained from the Pharmacy of the University Children's Hospital in Lublin } \\
\text { (price list as of 21.04.2020) }\end{array}$ \\
\hline The cost of valved holding chambers & The offer obtained from NZ Techno on 21.04.2020* \\
\hline The cost of nebulizers & $\begin{array}{l}\text { Data based on the purchase invoice of the OMRON A3 Complete }{ }^{\circledR} \text { and Intec Twister } \\
\text { Mesh }{ }^{\circledR} \text { for the needs of one of the departments at the University Children's Hospital } \\
\text { in Lublin (January 2020) }\end{array}$ \\
\hline Sterilization cost & $\begin{array}{l}\text { Data obtained from the Sterilization and Disinfection Department of the University } \\
\text { Children's Hospital in Lublin (price list as of 21.04.2020) }\end{array}$ \\
\hline Nurse's remuneration & $\begin{array}{l}\text { Announcement of the Speaker of the Sejm of the Republic of Poland of } 28 \text { June } 2019 \\
\text { regarding the publication of the consolidated text of the act on the method } \\
\text { of determining the lowest basic salary of certain employees employed in health care } \\
\text { entities }\end{array}$ \\
\hline $\begin{array}{l}\text { Time needed to complete the drug } \\
\text { delivery procedure with the use of } \\
\text { pMDI + VHC or NEB }\end{array}$ & $\begin{array}{l}\text { Time and motion study by Mason et al. [18] and the measured real time needed } \\
\text { to perform the inhalation procedure ( } 3 \text { min. for pMDI + VHC, } 7 \text { min for NEB with } \\
\text { a mesh nebulizer, } 20 \text { min for NEB with a constant-output jet nebulizer) }\end{array}$ \\
\hline $\begin{array}{l}\text { The cost of additional materials necessary } \\
\text { during the inhalation procedure } \\
\text { (gloves, disinfectant, syringes, needles) }\end{array}$ & $\begin{array}{l}\text { Data obtained from the hospital's financial department. } \\
\text { Guidelines for the use of personal protective equipment in accordance with the } \\
\text { in-hospital procedure "Inhalation medication using various aerosol therapy techniques" } \\
\text { (procedure number: PPO7/2018) }\end{array}$ \\
\hline
\end{tabular}

pMDI - pressurized metered-dose inhaler, VHC - valved holding chamber, NEB - nebulization; " main distributor of Trudell Medical International products in Poland.

Table 2. Characteristics of tested devices used during the aerosol therapy

AeroChamber Plus Flow-Vu ${ }^{\oplus}$ dual-valve, low-resistance, small-volume (149 $\mathrm{ml}$ ), antistatic system, fitted to all pMDI, visual and acoustic control of the inspiratory flow rate

RespiChamber Hospital ${ }^{\oplus}$ - dual-valve, low-resistance, small-volume (149 ml), antistatic system, fitted to all pMDI, possibility of high-temperature sterilization

OMRON A3 Complete ${ }^{\oplus}$ - constant-output jet nebulizer, $\mathrm{RV}=0.7 \mathrm{ml}$ nebulization rate $0.3-0.7 \mathrm{ml} / \mathrm{min} \mathrm{MMAD}$ of the aerosol cloud 3-10 $\mu \mathrm{m}$

Intec Twister Mesh ${ }^{\oplus}$ - active mesh nebulizer, membrane reverse cleaning system, RV = 0.1 ml, MMAD of the aerosol cloud $4.8 \mu \mathrm{m}$, battery powered

pMDI - pressurized metered-dose inhaler, RV - residual volume, MMAD - mass median aerodynamic diameter. 
Table 3. The cost of the drug and the device for its supply per inhalation procedure

\begin{tabular}{|c|c|c|c|}
\hline Drug/medical device & $\begin{array}{c}\text { Dose of the drug per inhalation } \\
\text { procedure (excluding RV of the } \\
\text { nebulizer)* }\end{array}$ & $\begin{array}{l}\text { The cost of buying } \\
1 \text { pack of the drug or } \\
1 \text { medical device }\end{array}$ & $\begin{array}{l}\text { Cost of the drug/medical device for one } \\
\text { inhalation procedure (excluding the cost } \\
\text { of the drug needed to fill the RV } \\
\text { of the nebulizer) }\end{array}$ \\
\hline $\begin{array}{l}\text { Berodua }^{\oplus}(\mathrm{NEB}) \\
(0.5 \mathrm{mg}+0.25 \mathrm{mg} / \mathrm{ml})\end{array}$ & $\begin{array}{c}0.38 \mathrm{mg}+0.19 \mathrm{mg} \\
(0.75 \mathrm{ml}=15 \text { drops })\end{array}$ & $\begin{array}{l}\text { PLN } 18.53 \\
(20 \mathrm{ml})\end{array}$ & PLN 0.70 \\
\hline $\begin{array}{l}\text { Berodual } N^{\oplus} \text { (pMDI) } \\
(50 \mu \mathrm{g}+21 \mu \mathrm{g} / \text { puff) }\end{array}$ & $\begin{array}{l}100 \mu g+42 \mu g \\
(2 \text { puffs })\end{array}$ & $\begin{array}{l}\text { PLN } 25.86 \\
\text { (200 puffs) }\end{array}$ & PLN 0.26 \\
\hline $\begin{array}{l}\text { Ventolin }^{\oplus}(\mathrm{NEB}) \\
(1 \mathrm{mg} / \mathrm{ml}, 2.5 \mathrm{ml} \\
\text { ampoules })\end{array}$ & $\begin{array}{c}2.5 \mathrm{mg} \\
\text { (1 ampoule) }\end{array}$ & $\begin{array}{c}\text { PLN } 14.18 \\
\text { (20 ampoules) }\end{array}$ & PLN 0.71 \\
\hline $\begin{array}{l}\text { Ventolin }{ }^{\oplus}(\mathrm{pMDI}) \\
(100 \mu \mathrm{g} / \text { puff) }\end{array}$ & $\begin{array}{l}200 \mu g \\
(2 \text { puffs })\end{array}$ & $\begin{array}{l}\text { PLN } 7.81 \\
\text { (200 puffs) }\end{array}$ & PLN 0.08 \\
\hline $\begin{array}{l}\text { AeroChamber } \\
\text { Plus Flow-Vu }\end{array}$ & NA & $\begin{array}{c}\text { PLN } 60.48 \\
\text { (100 gas sterilizations) }\end{array}$ & PLN 0.61 + PLN 7.35 (gas sterilization) \\
\hline RespiChamber Hospital $^{\oplus}$ & NA & $\begin{array}{c}\text { PLN } 61.02 \\
\text { (100 gas sterilizations) }\end{array}$ & PLN 0.61 + PLN 7.35 (gas sterilization) \\
\hline OMRON A3 Complete ${ }^{\oplus}$ & NA & $\begin{array}{c}\text { PLN } \\
150 \text { (1000 inhalations) }\end{array}$ & PLN 0.15 + PLN 7.35 (gas sterilization) \\
\hline Intec Twister Mesh ${ }^{\circledast}$ & NA & $\begin{array}{c}\text { PLN } 190 \\
\text { (1500 inhalations) }\end{array}$ & PLN 0.13 + PLN 5.25 (gas sterilization) \\
\hline
\end{tabular}

pMDI-pressurized metered-dose inhaler, NEB - nebulization, $R V$ - residual volume, NA - not applicable. *Based on the characteristics of the medicinal products (as of 20.04.2020).

Table 4. Total direct cost of the inhalation procedure using a combination of short-acting $\beta_{2}$-agonists with short-acting muscarinic antagonists depending on the type of the inhalation device (in PLN)

\begin{tabular}{|c|c|c|c|c|c|c|c|}
\hline Fenoterol + ipratropium bromide & $\begin{array}{l}\text { Cost of the } \\
\text { dose of } \\
\text { medicine to } \\
\text { be given to } \\
\text { the patient }\end{array}$ & $\begin{array}{l}\text { Cost of the } \\
\text { drug needed } \\
\text { to fill the } \\
\text { RV of the } \\
\text { nebulizer }\end{array}$ & $\begin{array}{l}\text { Cost of one } \\
\text { use of the } \\
\text { medical } \\
\text { device }\end{array}$ & $\begin{array}{l}\text { Cost of } \\
\text { additional } \\
\text { materials } \\
\text { (gloves, } \\
\text { disinfectant) }\end{array}$ & $\begin{array}{l}\text { Cost of } \\
\text { a nurse's } \\
\text { work }\end{array}$ & $\begin{array}{c}\text { Cost of } \\
\text { sterilization, } \\
\text { packaging, } \\
\text { hospital } \\
\text { transport }\end{array}$ & $\begin{array}{l}\text { Total direct } \\
\text { cost of one } \\
\text { inhalation } \\
\text { procedure }\end{array}$ \\
\hline $\begin{array}{l}\text { OMRON A3 Complete }{ }^{\circledR}(\mathrm{RV}=0.7 \mathrm{ml}) \\
\text { Drug: Berodual }{ }^{\circledR}(\mathrm{NEB})\end{array}$ & 0.70 & $0.65^{*}$ & 0.15 & 4.95 & 8.97 & 7.35 & 22.77 \\
\hline $\begin{array}{l}\text { Intec Twister Mesh } ®(R V=0.1 \mathrm{ml}) \\
\text { Drug: Berodual }{ }^{\circledR}(\mathrm{NEB})\end{array}$ & 0.70 & $0.09^{\star \star}$ & 0.13 & 4.95 & 3.14 & 5.25 & 14.26 \\
\hline $\begin{array}{l}\text { pMDI + AeroChamber Plus Flow-Vu® } \\
\text { Drug: Berodual N® (pMDI) }\end{array}$ & 0.26 & NA & 0.61 & 0 & 1.35 & 7.35 & 9.57 \\
\hline $\begin{array}{l}\text { pMDI + RespiChamber Hospital } ₫ \\
\text { Drug: Berodual N® (pMDI) }\end{array}$ & 0.26 & NA & 0.61 & 0 & 1.35 & 7.35 & 9.57 \\
\hline
\end{tabular}

NEB - nebulization, $\mathrm{pMDI}$ - pressurized metered-dose inhaler, $R V$ - residual volume, NA - not applicable. "The cost of $0.7 \mathrm{ml}$ of Berodual. "*The cost of $0.1 \mathrm{ml}$ of Berodual.

All costs were expressed in PLN and compared after converting the currencies with other analyses available in the literature.

\section{Results}

Based on the obtained data, the cost of inhalation drugs used in asthma exacerbation therapy and devices for their administration was calculated. According to the hospital price list of 21 April 2020, the payer paid PLN 0.08 for SABA and PLN 0.26 for SABA + SAMA administered via
PMDI per inhalation procedure. The same drugs used in NEB cost the hospital PLN 0.71 and PLN 0.70 respectively (without taking into account the cost of the drug needed to fill the RV of nebulizer) and were 8.9 and 2.7 times more expensive than drugs administered by $\mathrm{pMDI}$. Considering the lifetime of inhalation drug delivery devices, it was calculated that the cost of using VHC per treatment together with the costs of sterilization was PLN 7.96 (identical for both analysed $\mathrm{VHC}$ ). When using nebulizers, these costs were lower and amounted to: PLN 7.50 for a jet nebulizer and PLN 5.38 for a mesh nebulizer (Table 3). 
Table 5. The total direct cost of the inhalation procedure using short-acting $\beta_{2}$-agonists depending on the type of the inhalation device (in PLN)

\begin{tabular}{|c|c|c|c|c|c|c|c|}
\hline Salbutamol & $\begin{array}{l}\text { Cost of the } \\
\text { dose of } \\
\text { medicine to } \\
\text { be given to } \\
\text { the patient }\end{array}$ & $\begin{array}{l}\text { Cost of the } \\
\text { drug needed } \\
\text { to fill the } \\
\text { RV of the } \\
\text { nebulizer }\end{array}$ & $\begin{array}{l}\text { Cost of one } \\
\text { use of the } \\
\text { medical } \\
\text { device }\end{array}$ & $\begin{array}{c}\text { Cost of } \\
\text { additional } \\
\text { materials } \\
\text { (gloves, } \\
\text { disinfectant) }\end{array}$ & $\begin{array}{l}\text { Cost of } \\
\text { a nurse's } \\
\text { work }\end{array}$ & $\begin{array}{c}\text { Cost of } \\
\text { sterilization, } \\
\text { packaging, } \\
\text { hospital } \\
\text { transport }\end{array}$ & $\begin{array}{l}\text { Total direct } \\
\text { cost of one } \\
\text { inhalation } \\
\text { procedure }\end{array}$ \\
\hline $\begin{array}{l}\text { OMRON A3 Complete }{ }^{\circledR} \\
\text { (RV }=0.7 \mathrm{ml}) \\
\text { Drug: Ventolin }{ }^{\circledR}(\mathrm{NEB})\end{array}$ & 0.71 & $0.71^{\star}$ & 0.15 & 4.95 & 8.97 & 7.35 & 22.84 \\
\hline $\begin{array}{l}\text { Intec Twister Mesh }{ }^{\circledR} \\
\text { (RV }=0.1 \mathrm{ml}) \\
\text { Drug: Ventolin® (NEB) }\end{array}$ & 0.71 & $0.71^{\star \star}$ & 0.13 & 4.95 & 3.14 & 5.25 & 14.89 \\
\hline $\begin{array}{l}\text { pMDI + AeroChamber } \\
\text { Plus Flow-Vu® } \\
\text { Drug: Ventolin }{ }^{\circledR}(\mathrm{pMDI})\end{array}$ & 0.08 & NA & 0.61 & 0 & 1.35 & 7.35 & 9.39 \\
\hline $\begin{array}{l}\text { pMDI + RespiChamber } \\
\text { Hospital }{ }^{\circledR} \\
\text { Drug: Ventolin }{ }^{\circledR}(\mathrm{pMDI})\end{array}$ & 0.08 & NA & 0.61 & 0 & 1.35 & 7.35 & 9.39 \\
\hline
\end{tabular}

NEB - nebulization, $P M D I$ - pressurized metered-dose inhaler, $R V$ - residual volume, NA - not applicable. "The cost of 1 ampoule of Ventolin ${ }^{\oplus}$, of which $0.7 m l$ will be used to fill the RV of the nebulizer (drug loss =1.8 ml). "The cost of 1 ampoule of Ventolin", of which $0.1 \mathrm{ml}$ will be used to fill the RV of the nebulizer (drug loss $=2.4 \mathrm{ml}$ )

Tables 4 and 5 present the actual costs of one inhalation procedure, taking into account the cost of the drug needed to fill the RV of the nebulizer, the cost of additional materials used, and the remuneration of medical staff. The cost of SABA + SAMA supply varied depending on the choice of the inhalation method. The hospital incurred the lowest expenses related to drug supply with $\mathrm{pMDI}$ $+\mathrm{VHC}-\mathrm{PLN}$ 9.57. The cost of SABA+SAMA nebulization was 1.5-2.4 times higher (mesh nebulizer - PLN 14.26, jet nebulizer - PLN 22.77). The analysis of expenses related to SABA inhalation showed that regardless of the type of $\mathrm{VHC}$, the cost of one inhalation procedure with the use of pMDI was 1.6-2.4 times lower compared to NEB and amounted to PLN 9.39. The most expensive method of SABA administration for the payer was NEB using a constant-output jet nebulizer (PLN 22.84) (Tables 4 and 5).

\section{Discussion}

Short-acting $\beta_{2}$-agonists and their combinations with short-acting muscarinic antagonists (SAMA) are, next to corticosteroids (ICS), the most commonly used inhaled drugs in children [1, 2, 19-21]. They are used in the therapy of various diseases, although for many years they have been mainly used in the treatment of asthma [1-3]. According to the recommendations of GINA and the Polish Inhalation Guide, these drugs should be used when necessary in the event of an exacerbation of the disease and administered using PMDI + VHC or alternatively in NEB in both outpatient and hospital treatment $[1,2,5,22]$

Polish research results indicate that hospital treatment of asthma exacerbation in adults is 7.6 times more expensive than outpatient treatment. Moreover, it has been shown that the cost of pharmacotherapy constitutes only $20 \%$ of the direct costs associated with hospital treatment [23]. It is important to look for diagnostic and therapeutic methods that, with high efficiency, will enable the reduction of hospital treatment costs. A cost analysis was carried out for inhalation pharmacotherapy of airway obstruction in children with asthma exacerbation conducted in the non-invasive treatment ward of one of the university children's hospitals in Poland. For the administration of inhalation drugs, dual-valve, small-volume and low-resistance VHC are used, as well as nebulizers with high clinical efficiency (a constantoutput jet nebulizer with mass median aerodynamic diameter (MMAD) regulation function, and an active mesh nebulizer). There are many VHCs available on the Polish market with various parameters, applications and prices. However, only a few meet the criteria of a modern $\mathrm{VHC}$ recommended by experts for children. One of them is AeroChamber Plus Flow- $\mathrm{Vu}^{\oplus}$ - the most thoroughly tested in vitro and in vivo $\mathrm{VHC}$, and the most commonly used one in the world $[4,5,24]$.

The development of technology enabling the precise dosing of inhaled drugs has contributed to the increasingly frequent selection of NEB as aerosol therapy methods. This applies especially to newborns and infants. The role of mesh nebulizers, which generate homogeneous aerosol particles (monodisperse aerosol) and are characterized by low drug losses, short nebulization time and high predicted lung deposition, is becoming increasingly important [25-27].

Pollock et al.'s summary of the systematic reviews to date of the use of bronchodilators in children with asth- 
ma exacerbation clearly indicates that SABA are the safest and have the greatest clinical efficacy among inhaled anti-obstructive drugs. Application by patients of SABA with the use of $\mathrm{PMDI}+\mathrm{VHC}$ compared to NEB reduces the need for hospitalization of a child with bronchial obstruction < 3 years of age by $44 \%$, while in older children it shortens the duration of stay in the emergency department by about 30 min [3].

Research results also indicate that regardless of the method of calculation, the use of SABA with PMDI + VHC instead of NEB ensures a reduction in total costs both in the emergency department and the hospital ward. The cost of one inhalation procedure using PMDI + VHC was 18-63\% lower compared to the cost of NEB. Differences in expenditure were observed in all children with bronchial obstruction regardless of their age. The lower cost of SABA supply with the use of pMDI + VHC compared to NEB resulted mainly from: (i) shorter inhalation time (3 min for $\mathrm{pMDI}+\mathrm{VHC}$ vs. 20 min for NEB), and thus a lower cost of the nurse's work, (ii) greater clinical effectiveness of SABA administered via PMDI + VHC vs. NEB, which translates into a smaller number of additional procedures performed in the emergency department, shorter time of the child's stay in the emergency department and lower risk of hospitalization, (iii) higher efficiency of SABA packaging with pMDI vs. solution for NEB, and (iv) lower cost of additional materials (disinfectant liquid, gloves, syringes) needed for administering the drug via pMDI + VHC vs. NEB [10-15].

Our analysis has similar results. From the payer's perspective, the cheapest was inhalation using SABA with pMDI + VHC. It was also observed that regardless of the type of $\mathrm{VHC}$ and type of the anti-obstructive drug, the cost of one inhalation procedure using PMDI was 1.5-2.4 times lower compared to NEB.

The differences in expenses were related to the prices of drugs, devices for their administration, costs of sterilization, and the working time of medical staff. The cost of drugs in $\mathrm{PMDI}$ per inhalation procedure was almost 9 times (SABA) or 3 times (SABA + SAMA) lower than the cost of the same drugs for NEB. Israeli researchers have provided identical observations. Breuer et al. indicated that the estimated annual cost of SABA consumption in a solution for NEB in the paediatric ward of a university hospital was 2.5 times higher than the cost of SABA administration via $\mathrm{pMDI}+\mathrm{VHC}[14]$.

The cost of the inhalation procedure is also significantly affected by the possibility of using one device for administering drugs to different patients. While in the case of nebulizers this is widely used, VHC in some of the analysed studies were dedicated to one patient $[10,11]$. Salyer et al. have shown that the use of a new $\mathrm{VHC}$ in each patient resulted in more than a twofold increase in the cost of inhalation using PMDI [11]. In our hospital, VHC, similarly to nebulizers, undergo a gas sterilization process (ethylene oxide), which significantly reduces their operating costs [28]. However, the cost of using VHC per inhalation procedure is still higher than the cost of using a nebulizer once (PLN 0.61 vs. PLN 0.130.15). Moreover, the costs of purchasing and using a $\mathrm{VHC}$ are about 30\% higher when the drug is administered through a mask.

Researchers also note that the duration of drug administration has the greatest impact on the total cost of the inhalation procedure. Salyer et al. indicated that the time needed to prepare and administer the drug by $\mathrm{PMDI}$ + VHC was estimated at 13.2 min, while in NEB at 20.4 min [11]. In turn, in the work of Mason et al., whose data were used in our analysis, the administration of the drug via pMDI took less time (2-3 min) and the duration of NEB was estimated at $20 \mathrm{~min}$ [18]. The duration of inhalation procedure determines the expenses related to the work of the medical personnel involved in this procedure. Usually the person performing the inhalation procedure is a nurse. Her employment costs vary from one country to another. However, in each analysis, the estimated cost of a nurse's work was significantly higher during NEB vs. drug supply with the use of PMDI + VHC. In the study by Breuer et al. the estimated cost of a nurse's work on administering inhalation drugs to 250 patients with asthma exacerbation was calculated at $\$ 1,481$ when $\mathrm{pMDI}+\mathrm{VHC}$ was used and $\$ 7,407$ when the doctor recommended NEB [14]. According to our calculations, a nurse costs a payer 2.3 to 6.6 times more when a child receives antiobstructive drugs in NEB. In the USA, 3-year observations have shown that shortening the time of SABA administration by replacing NEB with drug supply via PMDI + $\mathrm{VHC}$ is associated with a reduction in total costs by up to $21 \%$ [11]. In Staggs et al. study it was shown that replacing SABA supply in NEB with $\mathrm{pMDI}+\mathrm{VHC}$ shortened the child's stay in the emergency department by over 30 min (faster relief of asthma exacerbation, reduction in the number of procedures performed), which resulted in savings of $\$ 213,532$ per year [12].

The analysis also showed differences in the scope of direct NEB costs depending on the type of the nebulizer used. It has been estimated that the real cost of NEB using a mesh nebulizer is 1.5 times lower vs. NEB using a constant-output jet nebulizer (Tables 4 and 5). These differences result from: (i) shorter working time of medical staff when performing NEB with a mesh nebulizer vs. a jet nebulizer (7 min vs. 20 min), (ii) 7 times smaller RV of the mesh nebulizer $(0.1 \mathrm{ml}$ vs. $0.7 \mathrm{ml})$, which translates into a lower cost of the drug needed to fill this space, (iii) lower cost of sterilizing the mesh nebulizer vs. jet nebulizer (smaller dimensions of the elements of the mesh nebulizer, which are gas sterilized).

In the University Children's Hospital in Lublin, inhalation procedures using SABA or SABA + SAMA are performed in 5 wards (neonate pathology ward, infant pathology ward, pulmonology, allergology, and intensive care unit). Assuming that about 6000 inhalation proce- 
dures are performed per year using PMDI + VHC with a mouthpiece instead of NEB, the estimated annual hospital savings would be approximately PLN 28,000-81,000.

\section{Conclusions}

In hospital treatment of asthma exacerbations, the direct cost of SABA or SABA + SAMA inhalation by PMDI $+\mathrm{VHC}$ is lower compared to the cost of NEB. The direct cost of SABA or SABA + SAMA nebulization when using a mesh nebulizer is lower compared to the cost of NEB of the same drugs carried out with a constant-output jet nebulizer. The actual cost of the inhalation procedure consists of direct medical costs (prices of drugs, devices for their administration, remuneration for medical staff) as well as direct non-medical costs (cost of personal protective equipment, sterilization of drug delivery devices). The working time of medical staff during the inhalation procedure is the component generating the highest cost for the hospital.

\section{Conflict of interest}

The authors declare no conflict of interest.

\section{References}

1. Global Strategy for Asthma Management and Prevention, Global Initiative for Asthma (GINA). Update 2019. https://ginasthma.org/wp-content/uploads/2019/06/ GINA-2019-main-report-June-2019-wms.pdf (accessed 30.05.2020)

2. Global Strategy for Asthma Management and Prevention, Global Initiative for Asthma (GINA). Update 2020. https://ginasthma.org/wp-content/uploads/2020/04/GINA-2020-fullreport_final-_wms.pdf (accessed 30.05.2020).

3. Pollock M, Sinha IP, Hartling L, et al. Inhaled short-acting bronchodilators for managing emergency childhood asthma: an overview of reviews. Allergy 2017; 72: 183-200.

4. Laube BL, Janssens HM, de Jongh FHC, et al. What the pulmonary specialist should know about the new inhalation therapies. Eur Respir J 2011; 37: 1308-31.

5. Emeryk A, Pirożyński M, Mazurek H. Polski Przewodnik Inhalacyjny (Polish Inhalation Guide). Via Medica, Gdańsk, Poland 2015.

6. Ari A, Fink JB. Guidelines for aerosol devices in infants, children and adults: which to choose, why and how to achieve effective aerosol therapy. Expert Rev Respir Med 2011; 5: 561-72.

7. Iramain R, Castro-Rodriguez JA, Jara A, et al. Salbutamol and ipratropium by inhaler is superior to nebulizer in children with severe acute asthma exacerbation: randomized clinical trial. Pediatr Pulmonol 2019; 54: 372-7.

8. Cates CJ, Welsh EJ, Rowe BH. Holding chambers (spacers) versus nebulisers for beta-agonist treatment of acute asthma. Cochrane Database Syst Rev 2013; 2013: CD000052.

9. Castro-Rodriguez JA, Rodrigo GJ, Rodríguez-Martínez CE. Principal findings of systematic reviews of acute asthma treatment in childhood. J Asthma 2015; 52: 1038-45.

10. Leversha AM, Campanella SG, Aickin RP, Asher MI. Costs and effectiveness of spacer versus nebulizer in young children with moderate and severe acute asthma. J Pediatr 2000; 136: 497-502.

11. Salyer JW, DiBlasi RM, Crotwell DN, et al. The conversion to metered-dose inhaler with valved holding chamber to administer inhaled albuterol: a pediatric hospital experience. Respir Care 2008; 53: 338-45.

12. Staggs L, Peek M, Southard G, et al. Evaluating the length of stay and value of time in a pediatric emergency department with two models by comparing two different albuterol delivery systems. J Med Econ 2012; 15: 704-11.

13. Goh AE, Tang JP, Ling H, et al. Efficacy of metered-dose inhalers for children with acute asthma exacerbations. Pediatr Pulmonol 2011; 46: 421-7.

14. Breuer O, Shoseyov D, Kerem E, Brooks R. Implementation of a policy change: replacement of nebulizers by spacers for the treatment of asthma in children. Isr Med Assoc J 2015; 17: 421-4.

15. Spin P, Sketris I, Hill-Taylor B, et al. A cost analysis of salbutamol administration by metered-dose inhalers with spacers versus nebulization for patients with wheeze in the pediatric emergency department: evidence from observational data in Nova Scotia. CJEM 2017; 19: 1-8.

16. Drummond MF. Guidelines for pharmacoeconomic studies: the ways forward. Pharmacoeconomics 1994; 6: 493-7.

17. Wang L, Zhong Y, Wheeler L. Direct and indirect costs of asthma in school-age children. Prev Chronic Dis 2005; 2: A11.

18. Mason N, Roberts N, Yard N, Partridge MR. Nebulisers or spacers for the administration of bronchodilators to those with asthma attending emergency departments? Respir Med 2008; 102: 993-8.

19. Soh JY, Ng B, Tan Z, et al. Ten-year prescription trends of asthma medications in the management of childhood wheeze. Allergy Asthma Proc 2014; 35: e1-8.

20. Zuidgeest MG, van Dijk L, Smit HA, et al. Prescription of respiratory medication without an asthma diagnosis in children: a population based study. BMC Health Serv Res 2008; 8: 16.

21. Poulos LM, Ampon RD, Marks GB, Reddel HK. Inappropriate prescribing of inhaled corticosteroids: are they being prescribed for respiratory tract infections? A retrospective cohort study. Prim Care Respir J 2013; 22: 201-8.

22. Smith C, Goldman RD. Nebulizers versus pressurized metered-dose inhalers in preschool children with wheezing. Can Fam Physician 2012; 58: 528-30.

23. Kokot M, Głogowski C, Szewczak A. Cost of asthma exacerbation in Poland. Alergia Astma Immunol 2004; 9: 106-12.

24. Dissanayake $S$, Suggett J. A review of the in vitro and in vivo valved holding chamber $(\mathrm{VHC})$ literature with a focus on the AeroChamber Plus Flow-Vu Anti-static VHC. Ther Adv Respir Dis 2018; 12: 1753465817751346.

25. Choi KH, Moon SH, Park SK, et al. Fabrication and characterization of medical mesh-nebulizer for aerosol drug delivery. Appl Sci 2018; 8: 604.

26. Dhand R. Nebulizers that use a vibrating mesh or plate with multiple apertures to generate aerosol. Respir Care 2002; 47: 1406-18.

27. Dolovich MB, Dhand R. Aerosol drug delivery: developments in device design and clinical use. Lancet 2011; 377: 1032-45.

28. Mendes GC, Brandão TR, Silva CL. Ethylene oxide sterilization of medical devices: a review. Am J Infect Control 2007; 35: $574-81$. 